NOTE: This is a self-archived preprint version of the paper, to be presented at Persuasive 2008, June 4-6, Oulu, Finland, and published in $\mathrm{H}$. Oinas-Kukkonen et al. (Eds.):

PERSUASIVE 2008, LNCS 5033, pp. 274 - 278, 2008.

C Springer-Verlag Berlin Heidelberg 2008

\title{
Design with Intent: \\ Persuasive Technology in a Wider Context
}

\author{
Dan Lockton, David Harrison, and Neville Stanton \\ School of Engineering \& Design, Brunel University, Uxbridge, Middx. UB8 3PH, UK \\ \{Daniel.Lockton, David.Harrison, Neville.Stanton\} @brunel.ac.uk
}

\begin{abstract}
Persuasive technology can be considered part of a wider field of 'Design with Intent' (DwI) - design intended to result in certain user behaviour. This paper gives a very brief review of approaches to DwI from different disciplines, and looks at how persuasive technology sits within this space.
\end{abstract}

\section{Introduction}

Persuasive technology (PT) is an example of design intended to result in certain user behaviour [8, p.1]: it is strategic, with defined behavioural outcomes in mind. Broadly reviewing the idea of using design to modify behaviour, a spectrum of approaches emerges; a common factor is designer intent, and thus the term Design with Intent (DwI) can be used. This paper aims to explore briefly how PT fits in this context of DwI, as a background to understanding more about its boundaries and potential.

\section{Perspectives on Design with Intent}

Approaches to DwI have differing terminologies and philosophies, but techniques from one discipline may be applied usefully in another. For example, the authors' research is in ecodesign, creating and testing the efficacy of products which 'cause' users to operate them more efficiently, informed by perspectives from different fields.

\subsection{A Review of DwI Across Different Fields}

Affordances and Constraints. In HCI and product design, expressions of DwI relate to affordances and perceived affordances, as outlined by Gibson [9] (and developed by Norman [23, pp.9-11]): the interactions facilitated by a product, system or environment, and shaping users' perception of what actions are possible. ${ }^{1}$ When the aim is intentional shaping of user behaviour, the term behaviour-shaping constraint is often used: constraints such as forcing functions (e.g. interlocks [23, pp.131-40, 203-6]), may be used alongside tactics such as selection of defaults [15] or making certain

\footnotetext{
${ }^{1}$ The slight disparity [20] between Gibson and Norman's definitions was later clarified by Norman [24]: his area of focus would be better termed perceived affordances. 
actions deliberately more difficult - slanty design [4]. Programmed learning, such as teaching machines [30], uses forcing functions to persuade users to solve problems.

Poka-yoke. In manufacturing, poka-yoke (Japanese: 'mistake-proofing') encompasses defensive design techniques developed by Shingo, originally intended to make 'zero defects' achievable in assembly processes [29]. In general, these can be classified as 'control' or 'warning' poka-yokes: control poka-yokes are constraints which force 'correct' behaviour - e.g. the bevelled corner on memory cards and 31/2" floppy disks - while warning poka-yokes reduce errors by alerting users when an incorrect step or condition occurs. There is an overlap with persuasion techniques such as reduction, tunnelling and kairos [8, Ch. 3] in terms of making correct behaviour 'easier'.

Philosophical Approaches. Behaviour-steering design has been proposed by Jelsma [11], following Akrich and Latour's discussions of 'scripting' behaviour into artefacts $[1,16]$. Jelsma gives an example of a dual-button toilet flush, scripting users to decide on their water usage [11]. Some 'design for behavioural change' research incorporates scripting [e.g. 18]. A rhetorical approach, outlined by Buchanan [6], holds that all design incorporates an argument or usage intention; as Redström [27] suggests, this may imply that all design is 'persuasive'.

Built Environment. Winner's question [33], "Do artefacts have politics?" is generally applied pejoratively to architectural examples, notably Moses' low parkway bridges [7] (preventing bus access, discouraging poorer visitors to a state park ${ }^{2}$ ). A ubiquitous example is the park bench with central armrest discouraging overnight occupation (e.g. by the homeless [19]). Approaches [e.g. 13] in the vein of Alexander's work [2], use defensible space [22], natural surveillance and sociopetal seating [31] to deter crime and encourage interaction. Traffic-calming draws from visual perception to shape behaviour, as does retail environment design: planograms [32], floorplans and retail atmospherics [28], can be used to route customers, persuading them to make certain purchases.

Digital Environment. Using architecture (of a system or space) to regulate user behaviour - architecture of control - has received much attention in digital contexts [14], where Lessig [17] popularised the "code is law" concept. The prevalence of technological protection measures (e.g. digital rights management) confirms that design promoting adherence to business models is on some corporate agendas; there is commonality with security, where the aim is to constrain user behaviour. Network architecture and traffic-shaping permit price discrimination [25], encouraging certain behaviours economically.

Other Commercial Strategies. Aside from advertising itself, DwI intended to extract greater value from consumers ranges from the reinforcement of the MOPy screensaver noted by Fogg [8, p.228], to the razor and blades model, where a product locks users into repeat consumable purchases. Electronic authentication, such as the handshake chips in some printer cartridges, extends this business model. Commercial DwI strategies also include planned obsolescence [26], persuading consumers to purchase replacements, and anti-features [10], intentionally degraded to persuade buyers to pay more for a 'better' model - 'artificial' product differentiation.

\footnotetext{
${ }^{2}$ Later research casts doubt over Moses' supposed intentions and the bridges' height [e.g. 12].
} 


\subsection{How Persuasive Technology Fits with DwI}

Much PT research focuses on persuasion with intended social benefit - from encouraging exercise [e.g. 21] to reducing energy use [e.g. 3], but in the wider DwI field, the intent is often commercial benefit. The aims are not mutually exclusive: e.g. a recycling company persuading users to recycle can have both social and commercial benefit intent. Hence it might be sensible to consider intended social benefit and intended commercial benefit as orthogonal dimensions of the DwI space (Figure 1). Another aspect is whether the impact on the immediate user is 'helpful' (the third dimension in Figure 1): e.g. making it difficult to put a TV on standby embodies social benefit intentions (energy saving), but will inconvenience individual users. This area is shown in grey in Figure 1, and is likely to contain more controversial examples; 'intended social benefit' itself will also be controversial in cases where the intent is politicised.

The dashed line thus suggests an approximate domain for PT in the DwI space, at least based on literature to date: centred on intended social benefit, usually (not always) helpful to the immediate user, and possibly with intended commercial benefit.

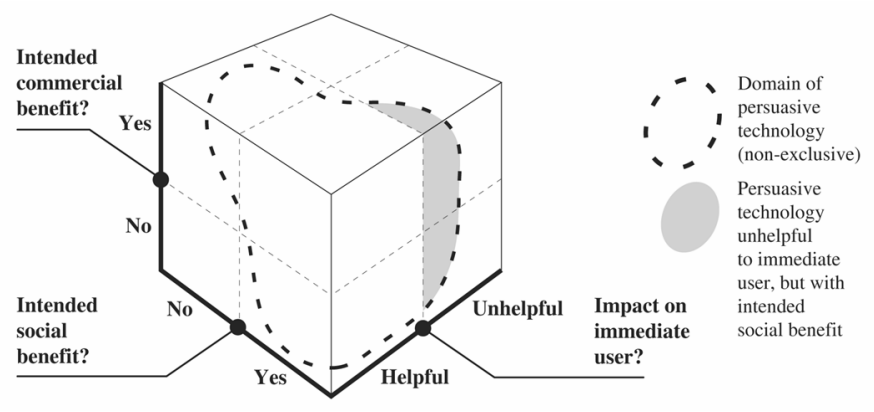

Fig. 1. Some possible dimensions of the wider DwI space, and how PT fits

The diagram only illustrates three possible dimensions, and does not address characteristics such as the degree of 'coercion' involved in a technique. This is a difficult semantic issue to consider definitively, since while 'persuasion' in a PT context is defined to exclude coercion [8, p.15], it is recognised that "the line between persuasion and coercion can be a fine one" [8, p.21]. In the wider field of DwI there are many examples (e.g. antihomeless benches) where a more coercive intent is demonstrated. If, as Redström [27] argues, all design is persuasive, then coercive design may simply be an 'unethical' subset, with its boundaries inevitably subject to analysis [e.g. 5], debate and possible revision.

\section{Conclusions}

While brief, it is hoped that the above review of the DwI field forms a useful and interesting background for further work in exploring how PT fits in this context of designing behaviour change. The main contribution is perhaps to bring an awareness 
of different DwI perspectives to PT researchers, with the possibility of informing or inspiring new strategies on further investigation.

Future work from the authors will expand on a range of persuasive design techniques for causing users to operate products in a more sustainable manner: selecting these, designing the systems, and testing their efficacy in user trials.

\section{References}

1. Akrich, M.: The De-Scription of Technical Objects. In: Bijker, W., Law, J. (eds.) Shaping Technology/Building Society, pp. 205-224. MIT Press, Cambridge (1992)

2. Alexander, C., Ishikawa, S., Silverstein, M., et al.: A Pattern Language, OUP, NY (1977)

3. Bång, M., Torstensson, C., Katzeff, C.: The PowerHouse: A Persuasive Computer Game Designed to Raise Awareness of Domestic Energy Consumption. In: IJsselsteijn, W., de Kort, Y., Midden, C., Eggen, B., van den Hoven, E. (eds.) PERSUASIVE 2006. LNCS, vol. 3962, pp. 123-132. Springer, Heidelberg (2006)

4. Beale, R.: Slanty Design. Commun. ACM 50(1), 21-24 (2007)

5. Berdichevsky, D., Neuenschwander, E.: Toward an Ethics of Persuasive Technology. Commun. ACM 42(5), 51-58 (1999)

6. Buchanan, R.: Declaration by Design: Rhetoric, Argument and Demonstration in Design Practice. Design Studies 2/1, 4-22 (1985)

7. Caro, R.A.: The Power Broker: Robert Moses \& the Fall of New York, A.A. Knopf, NY (1974)

8. Fogg, B.J.: Persuasive Technology: Using Computers to Change What We Think and Do. Morgan Kaufmann, San Francisco (2003)

9. Gibson, J.J.: The Ecological Approach to Visual Perception, pp. 127-143. Houghton Mifflin, Boston (1979)

10. Hill, B.M.: Anti-Features. FSF Blog (2007), http://www.fsf.org/blogs/community/antifeatures

11. Jelsma, J.: Design of Behaviour Steering Technology. In: Proceedings of the International Summer Academy on Technology Studies 2000, IFZ, Graz (2000)

12. Joerges, B.: Do Politics Have Artefacts? Social Studies of Science 29/2, 411-431 (1999)

13. Katyal, N.K.: Architecture As Crime Control. Yale Law Journal 111, 1039 (2002)

14. Katyal, N.K.: Digital Architecture As Crime Control. Yale Law Journal 112, 2261 (2003)

15. Kesan, J.P., Shah, R.C.: Setting Software Defaults: Perspectives from Law, Computer Science and Behavioral Economics. Notre Dame Law Review 82, 583-634 (2006)

16. Latour, B.: Where Are The Missing Masses? The Sociology of a Few Mundane Artifacts. In: Bijker, W., Law, J. (eds.) Shaping Technology/Building Society, pp. 225-258. MIT Press, Cambridge (1992)

17. Lessig, L.: Code and Other Laws of Cyberspace. Basic Books, New York (1999)

18. Lilley, D., Bhamra, T., Lofthouse, V.A.: Towards Sustainable Use: An Exploration of Designing for Behavioural Change. In: Feijs, L., Kyffin, S., Young, B. (eds.) Proc. DeSForM 2006, pp. 84-97 (2006)

19. Lockton, D.: Benches Archive (2005-8), http://architectures.danlockton.co.uk/category/benches/

20. McGrenere, J., Ho, W.: Affordances: Clarifying and Evolving a Concept. In: Proceedings of Graphics Interface 2000, Montreal, pp. 179-186 (2000) 
21. Nawyn, J., Intille, S.S., Larson, K.: Embedding Behavior Modification Strategies into a Consumer Electronic Device: A Case Study. In: Dourish, P., Friday, A. (eds.) UbiComp 2006. LNCS, vol. 4206, pp. 297-314. Springer, Heidelberg (2006)

22. Newman, O.: Defensible Space. Macmillan, New York (1972)

23. Norman, D.A.: The Design of Everyday Things, Rev. edn. Basic Books, New York (2002)

24. Norman, D.A.: Affordances, Conventions and Design. Interactions 6(3), 38-42 (1999)

25. Odlyzko, A.: The Evolution of Price Discrimination in Transportation and its Implications for the Internet. Review of Network Economics 3(3), 323-346 (2004)

26. Packard., V.: The Waste Makers. David McKay Co, New York (1960)

27. Redström, J.: Persuasive Design: Fringes and Foundations. In: IJsselsteijn, W., de Kort, Y., Midden, C., Eggen, B., van den Hoven, E. (eds.) PERSUASIVE 2006. LNCS, vol. 3962, pp. 112-122. Springer, Heidelberg (2006)

28. Rushkoff, D.: Coercion: Why We Listen to What 'They' Say. Riverhead Books, New York (1999)

29. Shingo, S.: Zero Quality Control. Productivity Press, Portland (1986)

30. Skinner, B.F.: Teaching Machines. Science 128-3330, 969-977 (1958)

31. Sommer, R.: Personal Space: The Behavioral Basis of Design, pp. 58-97. Prentice-Hall, Englewood Cliffs (1969)

32. Underhill, P.: Why We Buy: The Science of Shopping, pp. 77-78. Simon \& Schuster, New York (1999)

33. Winner, L.: Do Artifacts Have Politics? In: The Whale and the Reactor: A Search for Limits in an Age of High Technology, pp. 19-39. U. Chicago Press (1986) 